\title{
Identification of Undeployed Stent in the Left Main Coronary Artery After 3 Years on Optical Coherence Tomography
}

Thibault Ronchard, MD; Nicolas Combaret, MD; Guilhem Malcles, MD;

Pascal Motreff, MD, PhD; Géraud Souteyrand, MD
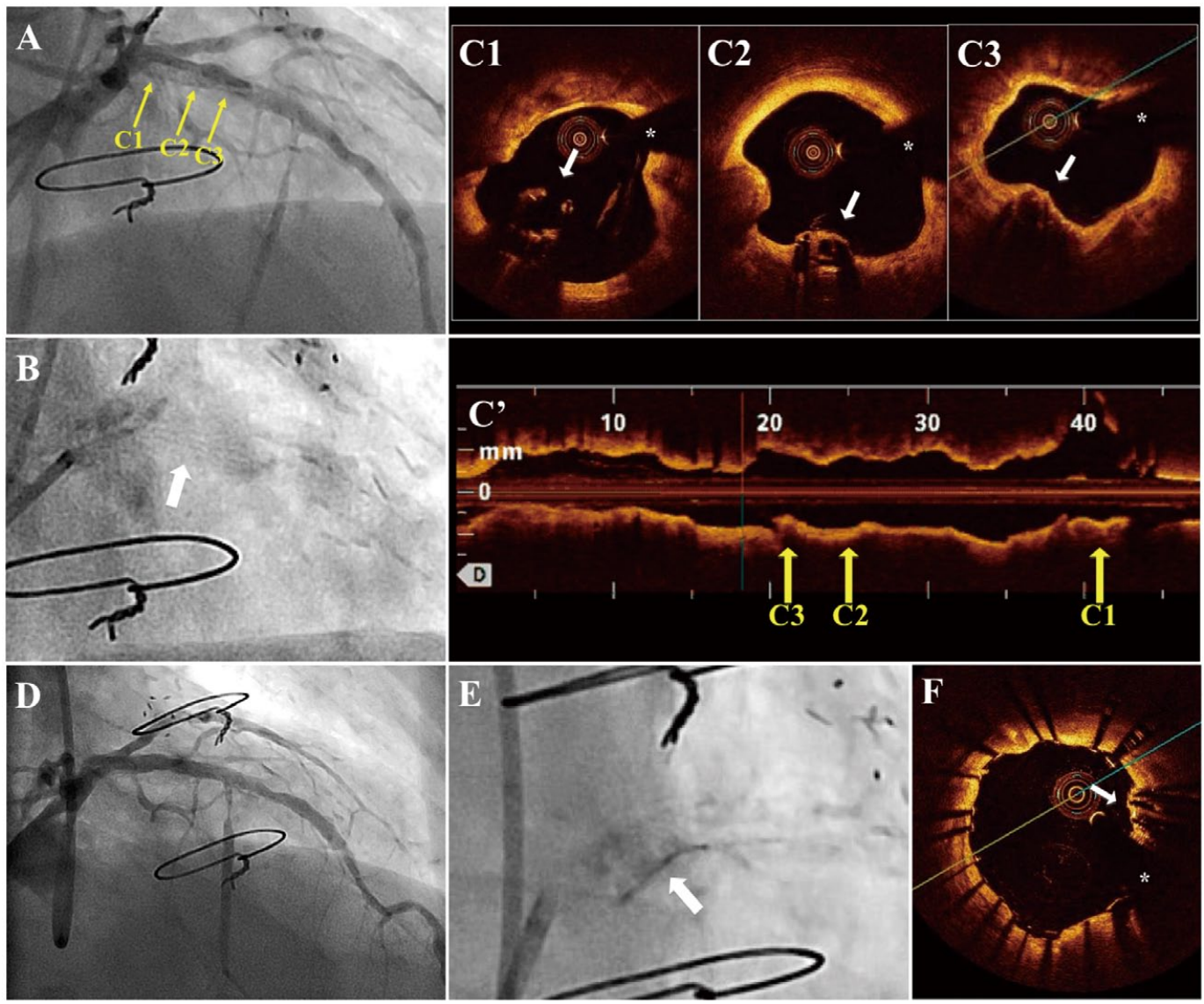

Figure. (A) Initial coronary angiography showing an area of fuzziness in the left main coronary artery and proximal part of the left anterior descending artery. (B) Angiography without iodinated contrast showing a questionable cylindrical image. (C1-C3) Optical coherence tomography (OCT) finding an undeployed stent from the left main artery to the proximal part of the left anterior descending artery. (C') Longitudinal view of this OCT. (D) Coronary angiography performed after stent implantation with the fuzziness artifact now absent. (E) Angiography without iodinated contrast showing the undeployed stent crushed between the artery wall and the new stent. (F) OCT showing good apposition of the new stent and a successfully crushed undeployed stent. *Wire artefact.

Received September 20, 2017; revised manuscript received November 9, 2017; accepted November 27, 2017; released online December 23, 2017 Time for primary review: 24 days

Cardiology Service, Clermont-Ferrand University Hospital, Clermont-Ferrand (T.R., N.C., G.M., P.M., G.S.); Pascal Institute, Clermont Auvergne University, Clermont-Ferrand (N.C., P.M., G.S.), France

Mailing address: Thibault Ronchard, MD, Centre Hospitalier Universitaire de Clermont-Ferrand, Service de Cardiologie, CHU Gabriel Montpied, 58 rue Montalembert, Clermont-Ferrand, France 63003. E-mail: thibault.ronchard@gmail.com

ISSN-1346-9843 All rights are reserved to the Japanese Circulation Society. For permissions, please e-mail: cj@j-circ.or.jp 
A 63-year-old man with ischemic heart disease (IHD) underwent triple coronary artery bypass grafting in 2009: right internal mammary artery to left anterior descending artery (LAD); left internal mammary artery to ramus intermedius; and saphenous vein to right coronary artery. Two months after surgery, the patient presented with non-ST-elevation myocardial infarction (NSTEMI). Coronary angiography showed 1 intact bypass (left internal mammary artery to ramus intermedius), with the others occluded. The middle LAD had two significant stenoses, one of which was at the beginning of the first diagonal branch (FDB). The FDB had 1 significant stenosis. The patient was treated by pre-dilatation with a $3 \times 20-\mathrm{mm}$ semi-compliant balloon (Sprinter ${ }^{\circledR}$ Legend $^{\circledR}$; Medtronic, Minneapolis, MN, USA) on the LAD at the beginning of the FDB. Then, two $3 \times 20-\mathrm{mm}$ drug-eluting stents (DES; Taxus Liberte ${ }^{\circledR}$, Boston Scientific, MA, USA) were implanted via the kissing stenting strategy. One stent was implanted, with difficulty, in the LAD, and the other was implanted from the LAD to the FDB.

The patient developed cardiogenic shock in association with the procedure; hence an intra-aortic balloon pump was implanted for 2 days and additional angioplasty of the middle LAD downstream of the FDB bifurcation was performed. This angioplasty included pre-dilatation with a $3 \times 20$-mm non-compliant balloon (Quantum ${ }^{\circledR}$, Boston Scientific) followed by implantation of a $3 \times 16-\mathrm{mm}$ DES (Taxus Liberte ${ }^{\circledR}$, Boston Scientific). The course was favorable. Dual antiplatelet therapy (DAPT) with clopidogrel and aspirin was maintained for 12 months and switched to aspirin monotherapy in the long term.

Three years later, this patient was referred to the present institution in 2012 for new-onset NSTEMI. Coronary angiography identified an FDB occlusion as well as an area of fuzziness in the left main coronary artery and proximal LAD (Figure A, yellow arrows). Given that these findings may be indicative of coronary calcification, rotational atherectomy was considered. At the location of the fuzziness, however, angiography without iodinated contrast agent showed a questionable cylindrical image (Figure B, white arrows). In addition, this angiogram showed a stent downstream (Taxus Liberte ${ }^{\circledR}$, Boston Scientific) implanted in 2009 (Figure B).

Prior to rotational atherectomy, endoluminal imaging was performed to clarify the fuzziness artifact. Optical coherence tomography (OCT) showed an undeployed stent covered by intima in the proximal part of the LAD (Figure C2,C3, white arrows) and free in the lumen of the left main artery (Figure C1, white arrow, C'; Movie S1). It was identified as the stent planned to treat the LAD in the 2009 kissing stenting procedure. On re-examination of the 2009 kissing stent angiography, we confirmed that both stents had originally been brought to the intended site, but that the stent to be implanted in the LAD has been lost, probably without the operators noticing this, in the context of the cardiogenic shock.
The undeployed stent was crushed on angioplasty with 4×20-mm non-compliant balloon (Quantum Apex ${ }^{\circledR}$, Boston Scientific), followed by the implantation of a $4 \times 23-\mathrm{mm}$ DES (Xience Prime ${ }^{\circledR}$, Abbott Vascular, CA, USA) from the left main coronary to the proximal LAD using the kissing balloon technique. The kissing balloon procedure was performed with 2 semi-compliant balloons (Sprinter ${ }^{\circledR}$ Legend $^{\circledR}$, Medtronic). A $3 \times 15-\mathrm{mm}$ balloon was positioned in the left main artery in the direction of the proximal LAD and a $2.5 \times 15-\mathrm{mm}$ balloon in the left main artery in the direction of the circumflex artery. The kissing procedure was difficult because of the sharp angle with the circumflex artery. Finally, the portion of stent in the left main artery was post-dilated with a $5 \times 12-\mathrm{mm}$ semi-compliant balloon (Trek ${ }^{\circledR}$, Abbott Vascular).

A good result was confirmed on coronary angiography with the fuzziness artifact now absent (Figure D). Angiography of the left main coronary and proximal LAD showed the undeployed stent crushed between the artery wall and the new stent (Figure E, white arrow). OCT confirmed the good angiographic result, showing good apposition of the new stent and a successfully crushed undeployed stent (Figure F, white arrow).

The patient was discharged uneventfully. DAPT with clopidogrel and aspirin has been maintained in the long term, due to the high risk of thrombotic events. At 5-year follow-up, the patient remained asymptomatic without progression of the IHD.

This case illustrates the value of OCT for guiding clinical and therapeutic decisions when angiography is inconclusive. ${ }^{1}$ It is interesting to note that the patient had no complications from the loose stent in the left main artery for 3 years, and without endoluminal imaging the stent might have remained unidentified. Endoluminal imaging is therefore an indispensable tool for guiding clinical and therapeutic decisions in the case of ambiguous angiography without a precise diagnosis.

\section{Disclosures}

P.M. and G.S. are consultants for St. Jude Medical. The other authors declare no conflicts of interest.

\section{Reference}

1. Prati F, Guagliumi G, Mintz GS, Costa M, Regar E, Akasaka T, et al. Expert review document part 2: Methodology, terminology and clinical applications of optical coherence tomography for the assessment of interventional procedures. Eur Heart J 2012; 33: $2513-2520$

\section{Supplementary Files}

Supplementary File 1

Movie S1. Run of the OCT (Figure C) finding an undeployed stent from the left main artery to the proximal part of the left anterior descending artery.

Please find supplementary file(s);

http://dx.doi.org/10.1253/circj.CJ-17-0985 